Int. J. Electrochem. Sci., 14 (2019) $3897-3915$

\title{
Corrosion Inhibition Efficiency of Cysteine-Metal ions Blends on Low Carbon Steel in Chloride-Containing Acidic Media
}

\author{
Abdualah Elhebshi ${ }^{1}$, Mohamed S. El-Deab ${ }^{2, *}$, Ahmed El nemr ${ }^{3}$ and Ibrahim Ashour ${ }^{1,4, *}$ \\ ${ }^{1}$ Chemical Engineering Department, Faculty of Engineering, Elminia University, Elminia, Egypt \\ ${ }^{2}$ Department of Chemistry, Faculty of Science, Cairo University, Cairo, Egypt. \\ ${ }^{3}$ Environmental Division, National Institute of Oceanography and Fisheries, Kayet Bey, Elanfoushy, \\ Alexandria, Egypt. \\ ${ }^{4}$ Zewail City, University of Science and Technology, 6th October City, Giza, Egypt \\ *E-mail: $\underline{\text { msaada68@yahoo.com, iashour@zewailcity.edu.eg }}$
}

doi: $10.20964 / 2019.03 .51$

Received: 11 September 2018 / Accepted: 18 December 2018 / Published: 10 March 2019

\begin{abstract}
This paper addresses the effect of some metal ions (e.g., $\mathrm{Cu}^{2+}, \mathrm{Ni}^{2+}$ and $\mathrm{Fe}^{2+}$ ) in their blends with cysteine (an environmentally friendly organic compound) on the inhibition efficiency (IE) of the corrosion of low carbon steel (LCS) in three different media, i.e., $0.5 \mathrm{M} \mathrm{H}_{2} \mathrm{SO}_{4}$ in the absence and the presence of 3.5 wt $\% \mathrm{NaCl}$ or $0.5 \mathrm{M} \mathrm{Na}_{2} \mathrm{SO}_{4}$. The results obtained from both electrochemical impedance spectroscopy (EIS) and electrochemical polarization measurements indicated a significant increase in $I E$ of cysteine in the presence of a few micro molar amounts of $\mathrm{Cu}^{2+}$ ions instead of cysteine alone. On the other hand, blending cysteine with $\mathrm{Ni}^{2+}$ or $\mathrm{Fe}^{2+}$ decreased $I E$. That is $I E$ reached ca. 90, 91 and $92 \%$ in the presence of $8 \mathrm{mM}$ cysteine and $25 \mu \mathrm{M} \mathrm{Cu}^{2+}$ ions in the first, second and third medium, respectively, compared to ca. $70 \%, 66 \%$ and $58 \%$ in the presence of cysteine alone (i.e., in absence of $\mathrm{Cu}^{2+}$ ions). Moreover, polarization experiments indicated that cysteine and $\mathrm{Cu}^{2+}$ ions blend acts as a mixed-type inhibitor for the corrosion of LCS. The formation of $\mathrm{Cu}(\mathrm{I})$-cysteinate complex and/or cysteine SAM at $\mathrm{Cu}$ atop the LCS surface (as evident from EDX and SEM results) protects the metal surface from exposure to the aggressive chloride ions. $I E$ of cysteine- $\mathrm{Cu}^{2+}$ blend remains effectively high with time indicating its high stability in the applied chloride-containing acidic media.
\end{abstract}

Keywords: Cysteine, Low Carbon Steel, EIS, green corrosion inhibitor, acid medium.

\section{FULL TEXT}

(C) 2019 The Authors. Published by ESG (www.electrochemsci.org). This article is an open access article distributed under the terms and conditions of the Creative Commons Attribution license (http://creativecommons.org/licenses/by/4.0/). 